INNOVATION, EFFICIENCY CYCLE, AND STRATEGY IMPLICATIONS

Harry Maier and Heinz-Dieter Haustein

International Institute for Applied Systems Analysis, Laxenburg, Austria

RR-82-22

May 1982

Reprinted from Technological Forecasting and Social Change, volume 17(1980)

INTERNATIONAL INSTITUTE FOR APPLIED SYSTEMS ANALYSIS

Laxenburg, Austria 
Research Reports, which record research conducted at IIASA, are independently reviewed before publication. However, the views and opinions they express are not necessarily those of the Institute or the National Member Organizations that support it.

Reprinted with permission from Technological Forecasting and Social Change 17: 35-49, 1980. Copyright $\odot 1980$ H. Maier et al.

All rights reserved. No part of this publication may be reproduced or transmitted in any form or by any means, electronic or mechanical, including photocopy, recording, or any information storage or retrieval system, without permission in writing from the copyright holder. 


\section{FOREWORD}

For some time the International Institute for Applied Systems Analysis has studied issues related to the management of technological innovation both from national and international points of view.

From 1978 to 1980 Professor Harry Maier from the Central Institute for Economics in Berlin, German Democratic Republic, was the leader of this work. From 1979 on Professor Heinz-Dieter Haustein of the Economic University of Berlin (GDR) has been a member of this group.

Their joint paper records some early findings of their research.

ALEC M. LEE

Chairman

Management and Technology Area 


\title{
Innovation, Efficiency Cycle, and Strategy Implications
}

\author{
HARRY MAIER and HEINZ-DIETER HAUSTEIN
}

ABSTRACT

Innovation research is now in its third stage, in which most attention is given to the efficiency cycle of industries. The five stages of this efficiency cycle (takeoff, rapid growth, maturation, saturation, and crisis) are very important for the firm's strategy and national innovation policy.

Innovation policy should take into account societal goals and objectives. A Social Opportunity Analysis (SOA) is especially important for determining future innovation fields, identifying new alternatives for structural change, and solving problems facing national economies and the entire world economy.

This paper tries to identify the universal and global challenges facing national innovation policy and firm strategy in many countries. Their conclusion is that we need a relationship between innovation policy and firm strategy that is able to give innovations a more concrete orientation toward human needs; to create social control procedures for unintentional, indirect, or delayed disadvantages of technology; to secure the interlinkage between technological and social innovation; and to contribute significantly to solving global problems. In this context we discuss the task's critical to improving the relationship between national innovation policy and firm strategy:

1. Consideration of the different roles of basic, improvement, and pseudo-innovations.

2. Information about future fields of innovation.

3. Exploration of the different side effects of innovation.

4. A strengthening of the scientific and educational infrastructure for innovation.

5. Improvement in the abilities of firms and society to deal with new circumstances and situations by developing new procedures of social and organizational innovative learning.

6. The realization that government actions concerning innovation can cause very different results in the different stages of the innovation process.

7. The global dimension of innovation.

\section{Introduction}

Innovation, the process of creation, development, use, and diffusion of a new product or process for new or already identified needs, has become one of the central themes

HARRY MAIER is the leader of the task group researching into the management of innovation at the International Institute for Applied Systems Analysis, A-2361 Laxenburg, Austria. This task group includes research scholars from the East and West. His homeland is the German Democratic Republic, where he was Deputy Director of the Central Institute for Economics in Berlin.

HEINZ-DIETER HAUSTEIN is also working in the Innovation Task Group at the International Institute for Applied Systems Analysis. He was Deputy Director of the Institute for Management, and Head of the Department for Planning and Forecasting of Science and Development at the Economic University of Berlin (German Democratic Republic). 
for both developed and underdeveloped countries. The causes and motivation for the growing concern about the status of innovative ability are very different.

Some countries that have taken the superiority of their technological ability for granted are now faced with a slowdown in the rate of productivity advance, with weakness in international competitiveness, high-priced energy and other natural resources, unemployment, inflation, and a tendency to stagnate. Other countries, which in the past were successful in generating social and technological change, now have to realize that the current economic environment, especially in the resource situation, needs new technological, managerial, and social approaches in order to deal with the new circumstances and thus fulfill the social goals that arise out of the nature of their society. Developing countries are faced with growing imbalances between their responsibility to secure and improve the living conditions of more and more people and their technological and social capability to use their natural and human resources to attain this. Despite the fact that shaping and promoting technological innovations has become a universal problem, the causes for the growing concern about innovation are not fully understood.

\section{Some Remarks on the Development of Our Thinking About Innovations}

The exploration of innovation was a process that has run through different phases of investigation in which different topics and analytical tools were dominant. The scientific results of all stages are now embodied in our current thinking about innovation. We assume that it is possible to distinguish between three phases in our efforts to understand better the innovation process over the last two decades.

The first phase of the innovation process started in the beginning of the 1960s when problems of management, planning, and forecasting of research and development (R\&D) activities; vertical and horizontal allocation of $R \& D$ resources within the national economy, between the different types, disciplines, and stages of R\&D; and the creative character of the innovation process were the main problems of the investigation. At this time many new research disciplines and new research directions were created, such as the "science of science" and "economics of research." More and more scholars were starting to identify the contribution of technological progress to meet national needs. The "production and distribution of knowledge"' and the attempt to measure its contribution to economic growth were main subjects of research at that time.

The next step began with the recognition that higher expenditure in $R \& D$ does not automatically result in a higher rate of innovation. It was especially recognized that any innovation is the result of a combination of need factors and technological means of meeting a given or latent demand. This places the attention of analysis on those factors that are influencing the creation of innovations. In this context it was obvious that an important time lag exists between inventions and their technical and commercial utilization. The result of this was a sequential model that stressed that R\&D is only one phase of the innovation process and that technical realization and commercialization are crucial for successful innovations. It was obvious that corporations and countries that are very successful in the first phase of the innovation process do not automatically gain the benefits of their R\&D efforts. Therefore many studies at that time placed emphasis on the better understanding of the links between different phases of the innovation process, invention, technical realization, and commercialization.

The third phase of innovation research, which started in the first half of the 1970s, began with the recognition that the demand for innovation of a production unit very much depends on the economic environment in which it has to operate and on the stage of 
development of that production unit. It was found that the relationship between innovations and the efficiency of the production unit that has adopted them has changed during the time of the production unit's development. One of the most important findings was that the high level of output and efficiency is not equal to a high innovation rate. To understand this, we should investigate more carefully the development of the efficiency of the production unit that has adopted the innovation, in comparison with the average efficiency of the production units as a whole in the production field. With this approach, it was possible to understand better the role of the different kinds of innovation during the innovation cycle, and the role of basic, improvement, pseudo-innovation, product and process innovations, and their influence on efficiency. This does not mean that we are trying to ignore the advantages that were gained in the other phases of research or that we believe that the problems that were explored in the first two phases have now lost their importance. We have only tried to demonstrate the direction that our efforts to understand better the innovation process were taking in the past, without ignoring the results that we found in this way. Ironically, the dialectic of our thinking brought us back to problems that economists such as David Ricardo, Karl Marx, and Josef Schumpeter have left us.

\section{Innovation and Efficiency}

To gain an understanding of the dynamics and causes of innovations, we need to explore better the changes in the attitudes of production units as the loci for innovation during the development of their efficiency. By efficiency we mean the output/input ratio that the production unit can realize within the given economic circumstances.

Therefore the development of the relationship between the efficiency of the production unit that has adopted the innovation and the average efficiency of all production units that are producing competitive goods to meet special needs is very crucial to an understanding of the different strategies of firms within the process of their development and the scope of opportunities for influencing them through the national innovation policy.

The dominance of special types of innovation (basic, improvement, or pseudoinnovation), the role of product and process innovations, the typical barriers and stimuli, and the appropriate management skills and tools very much depend on the stage of development of the ratio between these different types of efficiency.

We will try to demonstrate the usefulness of this approach with the following model (Fig. 1).

First, we develop an index of the relationship between innovation and production efficiency.

$e_{i}(t) \quad$ is the efficiency coefficient of production unit $i$, which adopted the innovation at time $t$.

$\tilde{e}(t) \quad$ is the coefficient of the average efficiency for the production system as a whole at time $t$.

$\mathrm{x}=\frac{\mathrm{e}_{\mathrm{i}}(\mathrm{t})}{\tilde{e}(t)}$ is the coefficient of the efficiency of an innovation process, which is ciency of the system.

Let us explain the relationship between these two coefficients in a more formal way.

We consider the set of all productive units $\left\{p u_{1}, \ldots, p u_{n}\right\}$ which produce a commodity that fulfills the same customer's need, and assume that the subset $\left\{p u_{1}, \ldots\right.$, $\left.p u_{r}\right\}$ adopts a certain innovation and the subset $\left\{p u_{r+1}, \ldots, p u_{n}\right\}$ does not. Now we are 


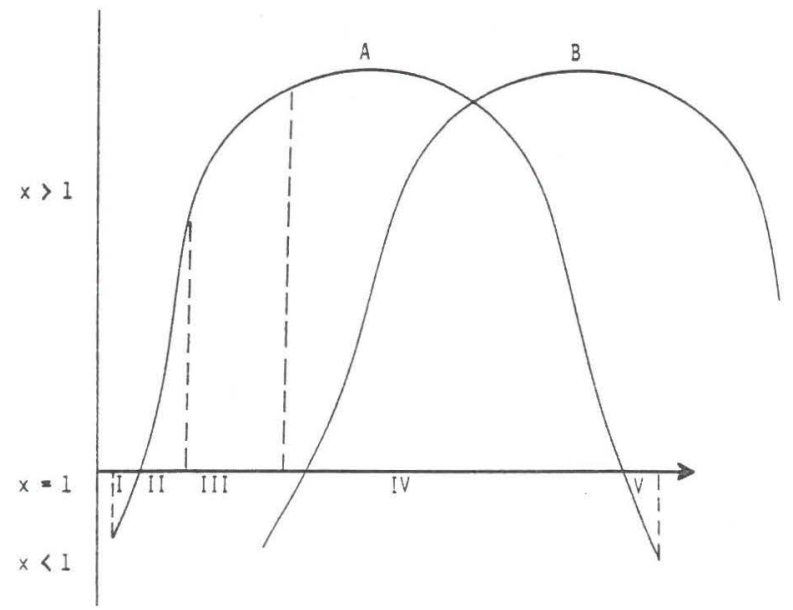

Fig. 1. Relation between the efficiency of an innovation process and the efficiency of the production system as a whole, over time. $x=e_{i}(t) / e(t)$, where $e_{i}(t)$ is the efficiency coefficient of the innovation process at time $t$ and $e(t)$ is the efficiency coefficient of the production system as a whole at time $t$.

interested in the development of the efficiency of the innovative subset $\left\{p u_{1}, \ldots, p u_{r}\right\}$ compared with the efficiency of the whole productive system $\left\{p u_{1}, \ldots, p u_{n}\right\}$.

We define $e_{i}(t)$ as the efficiency of the unit $p u_{i}$ at the time level:

$$
e_{i}(t)=\frac{\mathrm{O}_{i}(t)}{\mathrm{I}_{i}(t)},
$$

where $\mathrm{O}_{i}$ is the output to $p u_{i}$, and $\mathrm{I}_{i}$ is the input. Furthermore, the efficiency $e_{1}^{r}$ of the innovative subset is equal to $\sum_{i=1}^{r} e_{i}(t) p_{i}$, and the efficiency of the noninnovative subset is $\sum_{j=r+1}^{n} e_{j}(t) p$, where $p_{1}, \ldots, p_{n}$ are weights that fulfill $O<p_{i} \leqslant 1$.

Let us call $\tilde{e}(t)=\sum_{i=1}^{n} e_{i}(t) p_{i}$ the efficiency of the whole system, so that we get

$$
x(t)=\frac{e_{1}^{r}(t)}{\tilde{e}(t)}=\frac{\sum_{i=1}^{r} e_{i}(t) p_{i}}{\sum_{i=1}^{n} e_{i}(t) p_{i}}
$$

as the ratio of efficiency.

And as a result, we get

$$
x=\frac{e_{1}^{r}(t)}{\tilde{e}(t)}=\frac{O_{1}^{r}(t) I_{1}^{n}(t)}{I_{1}^{r}(t) O_{1}^{n}(t)},
$$

where $O^{j}{ }_{1}(t)\left(\operatorname{resp} I_{1}^{j}(t)\right)$, the average output (resp input) of the subset, is $\left\{p u_{1}, \ldots\right.$, $\left.p u_{j}\right\}$.

Figure 1 demonstrates that the development of $x(t)$ during the innovation cycle can indicate three fundamentally different situations for the firm.

$x(t)>1$ Here the efficiency of the firm that has adopted the innovation is much 
larger than the average efficiency of the production system as a whole. This is the growth phase of the production unit.

$x(t)=1$ Here the efficiency of the production unit that has adopted the innovation first is equal to the average efficiency of the entire production field. This is because many other production units are able to imitate and diffuse the innovation. This is the stagnation phase of the production unit.

$x(t)<1$ Here the $p u_{i}$ are not dynamic enough to change the direction of production after the adopted innovation has become mature and is not able to compare with the changes in the average efficiency through the advantages of the other production. This is the crisis situation for the production unit.

From our point of view it would be helpful for the analysis of the innovation process to distinguish five different stages in the development of the production unit that has adopted the innovations (see Table 1).

The requirements for a national innovation policy and the firm's strategy are rather different in these five stages. This is true for western market economies as well as for socialist planned economies. Forgetting about the specific stage of a given industry and using standardized approaches in organization, financing, strategy, planning or job recruitment, we cannot avoid big losses. Another important point is that the total benefits are highest in the maturation stage and still high in the saturation stage. The national economy cannot consist only of industry in the first two or three stages. It is necessary, however, to avoid the decline in the saturation stage leading to crisis by overcoming the inertness of this stage. Firm strategy at this stage should not be defensive, as it so often is, or pseudo-offensive, using traditional tools such as diversification and others.

In real cases the pattern of the five stages may be very different. Figure 2 shows the example of the lighting industry. For incandescent lamps the saturation stage of the generic product began before the Second World War, but owing to some partial innovations (e.g., halogen lamp), the transition to the crisis stage was avoided until now.

\section{Conclusions for National Innovation Policy and Firm Strategy}

The first conclusion that can be drawn from this model of the innovation cycle is that a high degree of efficiency and output of production is not an insurance against future disadvantages arising from an invasion of new technological options. The highest degree of efficiency, a large market share, a high degree of standardization, and vertical integration constitute the latest moment for a production unit that also will gain in future economic vitality and search for new ways to satisfy a latent demand or to satisfy an existing demand with better and less expensive alternatives. One of the most important experiences in the management of innovation in all industrialized countries is the importance of a close interdependency between government innovation policy and firm strategy. Government actions to stimulate innovations must not only be designed taking into account the change in attitude of production units as a result of improvements in their efficiency but also the adverse effects that may arise from the application and diffusion of technology to the working conditions, environment, security, and health of the people. On the other hand, corporations have to improve their ability to find appropriate responses to national needs and coming shortages and to avoid not only primary but also secondary and tertiary adverse effects of innovations. This system of interdependency is far from being 
TABLE 1

Stages in the Development of Industrial Organizations Creating and Adopting Innovations

\begin{tabular}{|c|c|c|c|c|c|c|}
\hline \multicolumn{2}{|l|}{ Characteristic } & Takeoff & Rapid growth & Maturation & Saturation & Crisis \\
\hline \multicolumn{2}{|l|}{ Example } & solar energy & microelectronics & chemistry & $\begin{array}{l}\text { synthetic fiber } \\
\text { industry }\end{array}$ & steel industry \\
\hline \multicolumn{2}{|c|}{$\begin{array}{l}\text { Predominant type of change in } \\
\text { production units }\end{array}$} & New establishments & Enlargements & Total modernization & Rationalization & Rationalization \\
\hline $\begin{array}{l}\text { Degree of technology } \\
\text { change }\end{array}$ & $\begin{array}{l}\text { Product } \\
\text { Process }\end{array}$ & $\begin{array}{l}\text { very high } \\
\text { low }\end{array}$ & $\begin{array}{l}\text { high } \\
\text { medium }\end{array}$ & $\begin{array}{l}\text { medium } \\
\text { high }\end{array}$ & $\begin{array}{l}\text { low } \\
\text { low }\end{array}$ & $\begin{array}{l}\text { very low } \\
\text { low }\end{array}$ \\
\hline \multicolumn{2}{|c|}{$\begin{array}{l}\text { Technological policy for growth } \\
\text { mainly oriented toward }\end{array}$} & push & $\begin{array}{l}\text { push and } \\
\text { compensation }\end{array}$ & compensation & $\begin{array}{l}\text { compensation and } \\
\text { continuation }\end{array}$ & $\begin{array}{l}\text { compensation and } \\
\text { continuation }\end{array}$ \\
\hline \multicolumn{2}{|l|}{ Relative efficiency } & low & very high & high & middle & very low \\
\hline \multicolumn{2}{|l|}{ Total benefits } & negative & low & very high & high & low or negative \\
\hline \multicolumn{2}{|c|}{ Substitution of labor by capital } & negative & $\begin{array}{l}\text { low (high demand for } \\
\text { qualified personnel) }\end{array}$ & $\begin{array}{l}\text { high (high demand for } \\
\text { less qualified } \\
\text { personnel) }\end{array}$ & very high & low \\
\hline \multicolumn{2}{|l|}{ Firm strategy } & creative push & $\begin{array}{l}\text { offensive long-term } \\
\text { oriented }\end{array}$ & market-oriented & $\begin{array}{l}\text { defensive or } \\
\text { pseudo-offensive }\end{array}$ & defensive \\
\hline \multicolumn{2}{|l|}{ Management } & $\begin{array}{l}\text { flexible risk-taking } \\
\text { creative }\end{array}$ & $\begin{array}{l}\text { flexible risk-taking } \\
\text { entrepreneurship }\end{array}$ & $\begin{array}{l}\text { less flexible rigid } \\
\text { organization }\end{array}$ & $\begin{array}{l}\text { risk-avoiding rigid } \\
\text { organization }\end{array}$ & $\begin{array}{l}\text { Preference of strong } \\
\text { leadership }\end{array}$ \\
\hline
\end{tabular}


perfect. It cannot be improved in a straightforward manner by investing more heavily in science and technology without considering the following.

The rate and benefits of innovations are very much dependent on the relationship between different types of innovation.

The stage of efficiency development of the production unit greatly determines the demand for special kinds of innovation.

The different side effects of technology must be explored to implement measures stimulating the positive effects of the technology by blocking the disadvantages.

The scientific and educational infrastructure of a country is a decisive precondition for innovation.

Government actions concerned with innovation cause very different results in different stages of the innovation process.

The need exists for a global dimension for innovation policy.

The relationship between product and process innovation is very much determined by the stage of development of the innovation process. Recently Abernathy [1] showed the relationship between product and process innovation using the example of the automobile industry. Figure 3 demonstrates the relationship using the example of incandescent lamps. This basic innovation reached its peak efficiency growth before the First World War. Further development in this field concentrated more on process innovations. We have just seen that on the level of the production unit the distinction among major product, major process, and incremental innovation is very important. On the macroeconomic level, however, it is very difficult to distinguish between major product and major process innovation; because a product of one firm may be the process equipment, components for assembly, or materials used by another firm. Therefore we think that on the macroeconomic level the distinction between basic innovation, improvement innovation, and pseudo-innovation is much more important [5]. Basic innovations are innovations that create a new efficiency potential and open new fields and directions for economic activities. The main function of improvement innovations is absorption of this efficiency potential through balancing and improving the given system. Most are incremental inno-

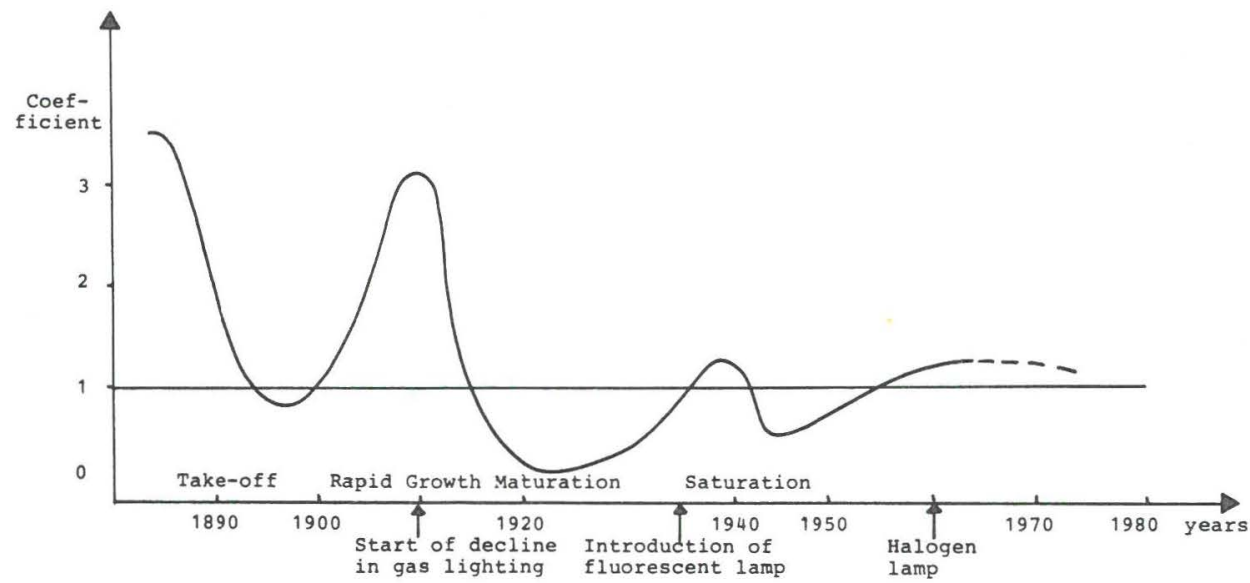

Fig. 2. The relation between the annual increases in efficiency of the lighting industry (incandescent lamps) and electrical engineering. 


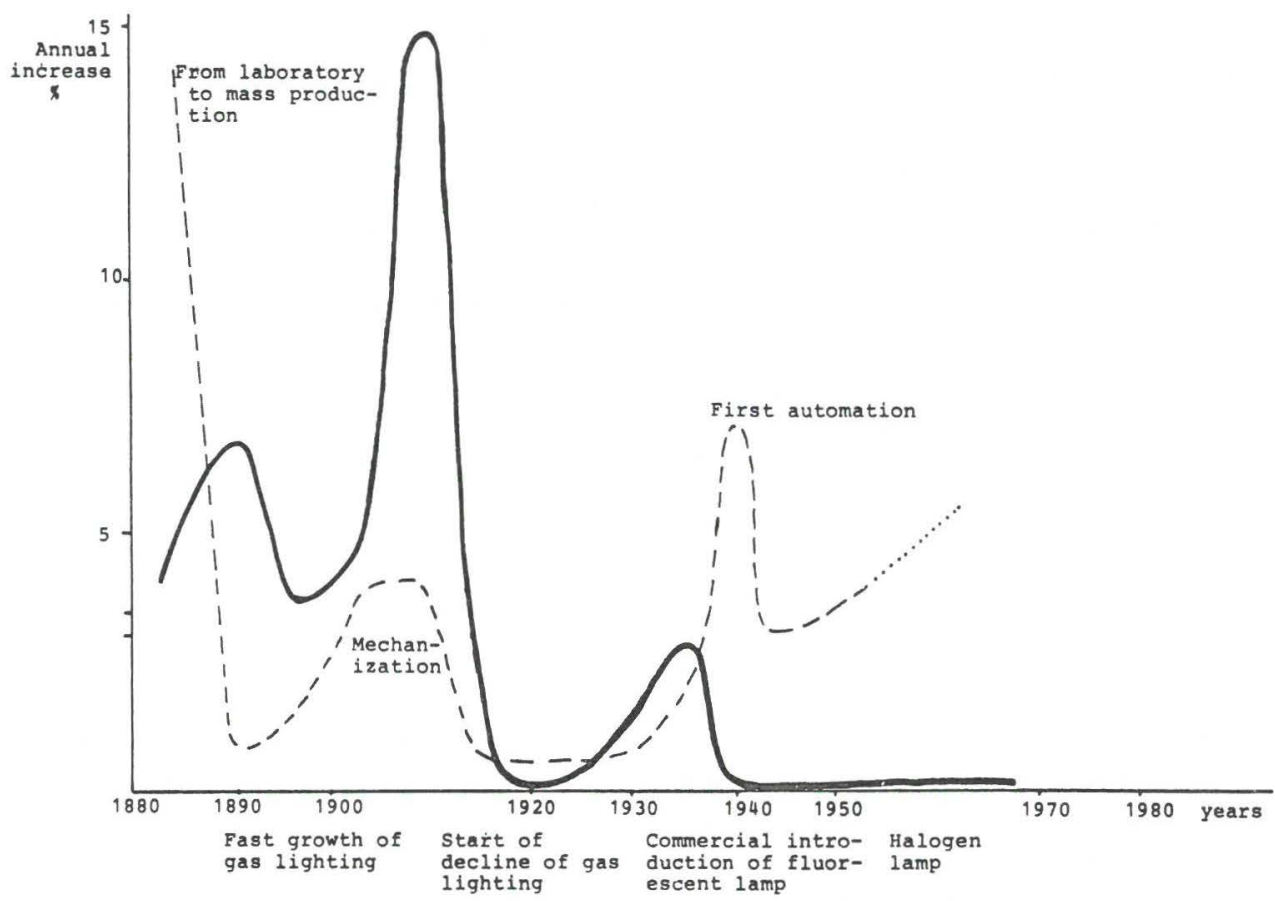

Fig. 3. The sequence of product and process innovation for the case of incandescent lamps.

vations. The improvement innovations become pseudo-innovations at the point when they are unable to secure efficiency of the production unit higher than the average efficiency of the whole system.

It is possible to demonstrate the role of basic, improvement, and pseudo-innovations with a model similar to that for the development of efficiency for the production unit. From a macroeconomic standpoint the national economy or the world economy is an integrated production system of resource usage.

We have already explained the efficiency coefficient $x(t)$.

$$
x(t)=\frac{e_{1}^{r}(t)}{\tilde{e}(t)}=\frac{O_{1}^{r}(t) I_{1}^{n}(t)}{I_{1}^{r}(t) O_{1}^{n}(t)},
$$

where

$x(t)$ is the coefficient of efficiency of the production units that have adopted innovations, compared with the efficiency of the entire production system in time $t$,

$e_{1}^{r}(t)$ is the efficiency of the production units in time $t$ that have adopted innovations,

$\tilde{e}(t)$ is the average efficiency of all production units within the entire production system at time $t$,

$O_{1}^{r}(t)$ and $I_{1}^{r}(t)$ are the average output respective to input of all innovative subsets at time $t$, and

$O_{1}^{n}(t)$ and $I_{1}^{n}(t)$ are the average outputs respective to input of all production units of the entire production system at time $t$. 
With this model we can identify three different situations:

$x(t)>1$ is a situation in which the production system is able through basic and improvement innovations to gain advantages in the growth of efficiency. The process of absorption of efficiency potential created through basic innovation at first accelerates the growth rate of efficiency, but after some time the growth rate will diminish.

$x(t)=1$ is a situation in which the absorbing process of efficiency potential, created through basic innovation, runs dry. The improvement and incremental innovations are unable to compare the decrease in average efficiency with higher resources and infrastructure costs. This is the "stalemate of technology"' [10].

$x(t)<1$ is a situation in which the production process is unable to respond to new resource situations and economic circumstances with structural changes capable of opening new fields and directions for economic activity. The result is that the efficiency will not only stagnate but also decrease. If society is urrable to implement a new push of innovations, this could be the starting point for a process of "deindustrialisation" (Freeman).

It is beyond the scope of this article to discuss the problems of the existence of "long waves." Important indications of their existence were discovered by Kondratieff [8] earlier this century. Other scholars have confirmed these findings; however, the explanation for the driving forces of this phenomenon still remains an unsolved problem. Nevertheless, much efforts was made to create a body of ideas and dates so that we now have some evidence by which to assume that the relationship between innovation and structural change is an important driving force of the "long wave" phenomenon. The relationship between the basic resource and the efficiency of industrial and agricultural production is especially important within this context. This can also explain why the development of resource and food prices is an important indicator for the existence of long waves.

It is evident that the world economy is not currently in an upward swing. Problems that now face us, such as shortages of energy and food, environmental burdens, diminishing growth rates of efficiency, and significantly lower returns of investment, are very clear indications of this. Only with the help of appropriate basic technological and social innovations is it possible to change this situation. This means that we need technological innovations that are able to open new directions for better use of natural and human resources, creation of new technological options to substitute scarce resources, and more rational combinations among existing resources.

On the other hand, we need social innovations that are able to stimulate creation, realization, and diffusion of these technological options and to avoid the undesired effects and wastage of resources through parasitic forms of consumption.

Innovation cannot be a goal in itself. The diffusion of an innovation spreads the advantages of the innovation through many production units and countries, resulting in the fact that the "monopoly rent" or "extra profit" of the first innovator will be relatively short. However, this will improve the average efficiency in many countries and the capability of more production units to produce more rationally so as to save resources and to supply more goods to meet those needs as yet unsatisfied.

To save their benefits from innovations, corporations in several countries try to transfer mature, standardized technologies and to use lower wages and nonexistent or 
loosely enforced government regulations concerning environment, health, and safety requirements. They have established a network of subsidiaries located in developing countries. The result of this is the well-known "dual economy" in developing countries, which is not able to contribute significantly to solving the problems that face these countries [6]. The necessity obviously exists to find a new way of transferring technology that is able on the one hand to help developing countries develop their own technological basis, and on the other hand to improve the average efficiency of the entire resource using the system of the world economy. Such a technology transfer could be the global dimension of the innovation policy.

The global dimension of the innovation policy has to play an important part in improving the capability of society in dealing with new circumstances and situations through the development of new procedures for social innovative learning. It could be disastrous and fatal in our time of growing global interdependency to learn only by shock. Social innovative learning means that our main concern should not be to find the best alternatives among given alternatives, but to emphasize the creation of new options able to solve the fundamental problems that we now face. Social innovative learning can not be adaptive but must be anticipatory [7]. Whereas adaptive learning is only our reactions to external pressure, anticipatory learning tries to create new alternatives at a time when events, circumstances, and environment are not yet irreversible. However, anticipatory social learning requires not only the judgments of experts and technocrats, but also the participation of people who are the subject and object of the innovation process. In all countries we have a significant demand by the people for their participation. A growing portion of the population wants to be involved in the process of judgment, assessment, and decision concerning technology that has tremendous consequences for their and humankind's future. This is a positive response to the growing complexity and international interdependency of the technological innovation process. If this is sometimes expressed in a rather irrational way, it only indicates our commitment to search for new forms for the distribution of knowledge to and cooperation and dialogue with a broader range of the population about the social consequences of innovation. But this also requires an openness to reevaluate the given social and economic structure, social and cultural values, and goals. We are convinced that the investigation of innovative learning of social systems on the firm, national, and global levels will become one of the most important problems for future research about innovations.

Social, organization, and technical innovations are different parts of a joint system. Without technological change it is impossible to alter the organizational and social system. On the other hand, technological innovations without organizational and social innovations will not improve the living conditions within the national and global framework. The need to consider both the social and technical sides of innovation has important consequences for our methodological approach. On the one hand, we can start from single technological change and look at its social consequences and implications or at the governmental measures needed to ensure its efficiency. This is, for example, the main aim of technology assessment (TA). On the other hand, we can start from social needs and goals, from existing and forthcoming leaks or bottlenecks in resource processing systems, and then look at the given field of technical possibilities for a technological fix. We can call this latter approach socioeconomic opportunity analysis (SOA) (Fig. 4 and 5).

The analysis of social opportunity is especially important for determining future 
fields of innovation, identifying new alternatives for structural change, and solving problems facing national economies and the entire world economy. This makes SOA an important tool for innovation learning in society and the global community. The International Institute For Applied Systems Analysis (IIASA) energy study is an interesting example of the analysis of social opportunity for a global problem [3, 9].

Innovation is a combination of user need and a technological means of meeting that need. Often the information of the need development or technological feasibilities lies outside the organizations that are able to generate and implement the innovation. Therefore one of the most important measures in promoting and shaping innovation from the government point of view must be to provide and distribute information about the development of regional, national, and global needs. It is necessary to make national and global needs more evident for the firm and to avoid contradictions between short-term corporation goals and long-term national needs. Thus government innovation policy - as the major part of the economic policy of a country - cannot only be concerned with the flow of resources toward high productivity industries, but must also try to identify the future fields of innovation and to create a social procedure for ensuring that the country's economy is prepared to deal with new national and global circumstances.

The degree of openness to new ideas concerning needs and technical options is an important precondition for a firm's innovation activity. This requires an efficient information flow among organizations. The recognition of needs often stimulates entrepreneurs to search for technical resources and information to meet the need. It is not so much the establishment of formal "pipelines" of knowledge from different sources, but more the establishment of close interaction between basic research institutes, applied research institutes, and production units that is necessary.

The adoption of innovations tend to depend very much on the degree of qualifications of management and labor forces within production units. Most developed countries have

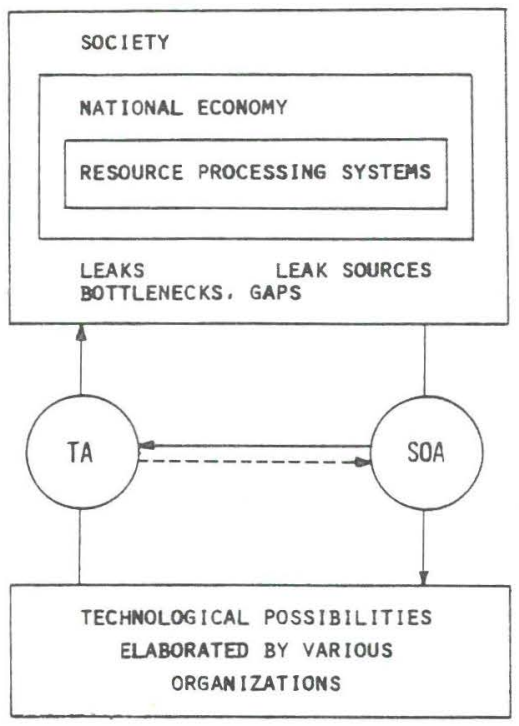

Fig. 4. The roles of TA and SOA. 


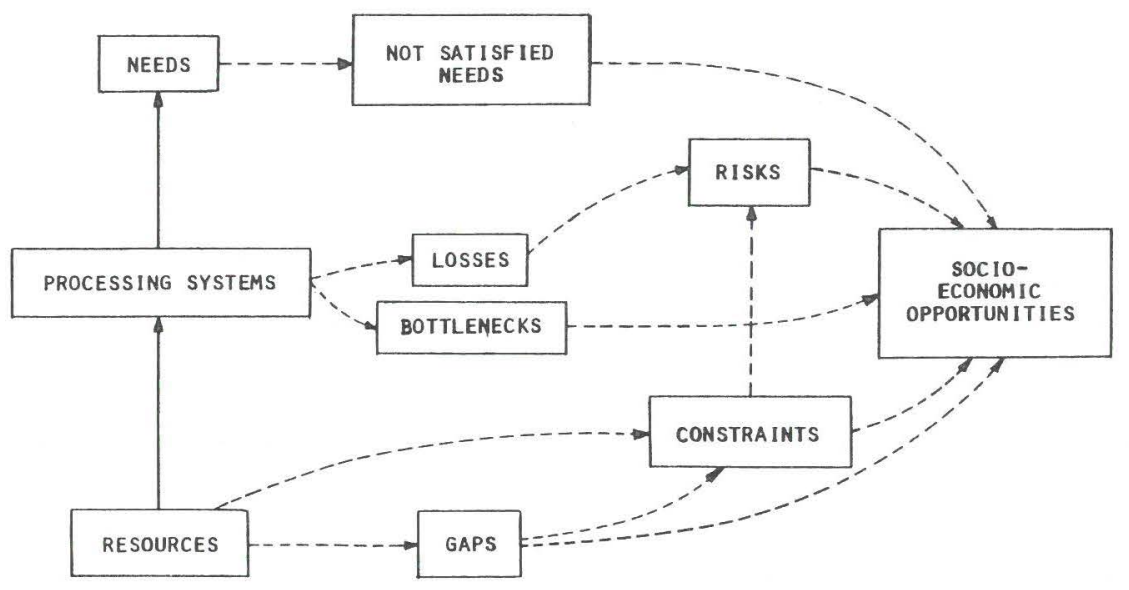

Fig. 5. SOA in the context of national problems.

had a significant improvement in the quality of human resources over the last two decades. On the one hand, the higher quality of human resources is an important precondition for technological and social innovation, and on the other hand, it is not possible to approach a higher quality of human resources without social and technological innovations. The creation of conditions in which the quality of human resources can grow and become a decisive social and economic force is a crucial point in national innovation policy. In the GDR, for example, in the period between 1962 and 1975 the growth rate of educational funds (human capital) was essentially higher than that of the funds of fixed assets.

By this GDR industry could nearly double its share in the total of university graduates in the period 1962-1975. In 1962 every tenth university graduate of the GDR economy worked in industry; today it is every fifth.

An important related problem is the employment of working people according to their qualifications and the use of these qualifications to implement, control, and manage technical innovations. Two important preconditions are necessary for this.

First, the education process must become more creative. If the supply of knowledge is not connected with the development of the capability of independent thinking and the production of sound educational motives, then these faculties, which are decisive for dealing with social and technological innovation, remain underdeveloped. Innovative learning demands development of the capability of independent and creative thinking and an optimistic attitude toward participation in the solution of technical, social, and cultural problems.

Second the educational system must be better used for the transfer of technology and developing skills to recognize needs and technological feasibilities and to assess the different sides of technical innovations. This should be an especially important part of in-service training. If in-service training is too tightly bound to direct organizations and task groups in the workplace, it cannot fulfill its function of stimulating creative thinking and innovative skills.

The high efficiency of social expenditures for education and improving qualifications can also be seen in close connection between increased qualification level and a growing 
contribution of the innovator's movement to efficiency of the national economy. The benefit of the innovator's movement (more than $50 \%$ of the prime cost reduction in GDR industry results from it) per unit of educational funds was 2.5 times higher in 1971-1975 than during the period 1960-1965 (Fig. 6).

Another lesson from the innovation cycle model is that national innovation policy and corporation strategies that try to achieve 1) stable development of efficiency in connection with the necessary structural changes and 2) competitiveness of production, while avoiding resource wastage, securing workplaces and avoiding stagflation, will have to put more emphasis on the coordination of the innovation cycle.

National innovation policy in particular must realize that the stimulation of different kinds of innovation also needs different kinds of actions. Despite these measures to improve the climate and conditions for innovation, national innovation policy can influence the innovation process through two types of actions.

1. Technology push actions-directly supporting the development of new technology or modification of existing technology

2. Technology pull actions - such as product characteristic interventions and market modification actions

Without doubt, the current status of nuclear energy, computer, aircraft, space technology, and communication systems is very much the result of the technology push actions of government. In the future, technological push will also remain important, especially in stimulating the initiation of various synthetic fuel technologies, such as coal gasification, and technologies to protect the environment and improve the communication system. Technology pull actions through product characteristic interventions are used in both market and planned economies to achieve better use of resources and to avoid undesirable side effects. For example, the GDR five-year plan (1976-1980) required firms to reduce the final energy coefficient of production through technological improvements by $2.8-3 \%$ per year. Other product characteristic interventions through limitations in the environment, pollution, materials and energy consumption, and so on play an important role in shaping technological development.

Market modification with the help of price policy plays an important role in stimulating innovations, but obviously it is necessary to define the purpose clearly, and to identify the side effects of such actions. In this context it is necessary to know what will be the impact of the actions of the entire innovation cycle and the firm attitude in special phases of that cycle. Otherwise government actions will not produce the results that they were ostensibly intended to achieve.

It is not possible to stimulate innovations with technology push actions only. The risk is too high to support technology that will not be accepted by the market. But it is also dangerous to wait for the impact of market forces, because we may not receive a suitable solution at the right moment, or when the moment is right we might not receive the right solution.

It is obvious that technology push actions could be very helpful in the innovation process in stages I and II, but they will have no influence on stages III-V. Technology pull actions can be helpful in stages II-IV, but they can be misleading to management in stage $\mathrm{V}$ (protectionism) and uninfluential in stage I. 


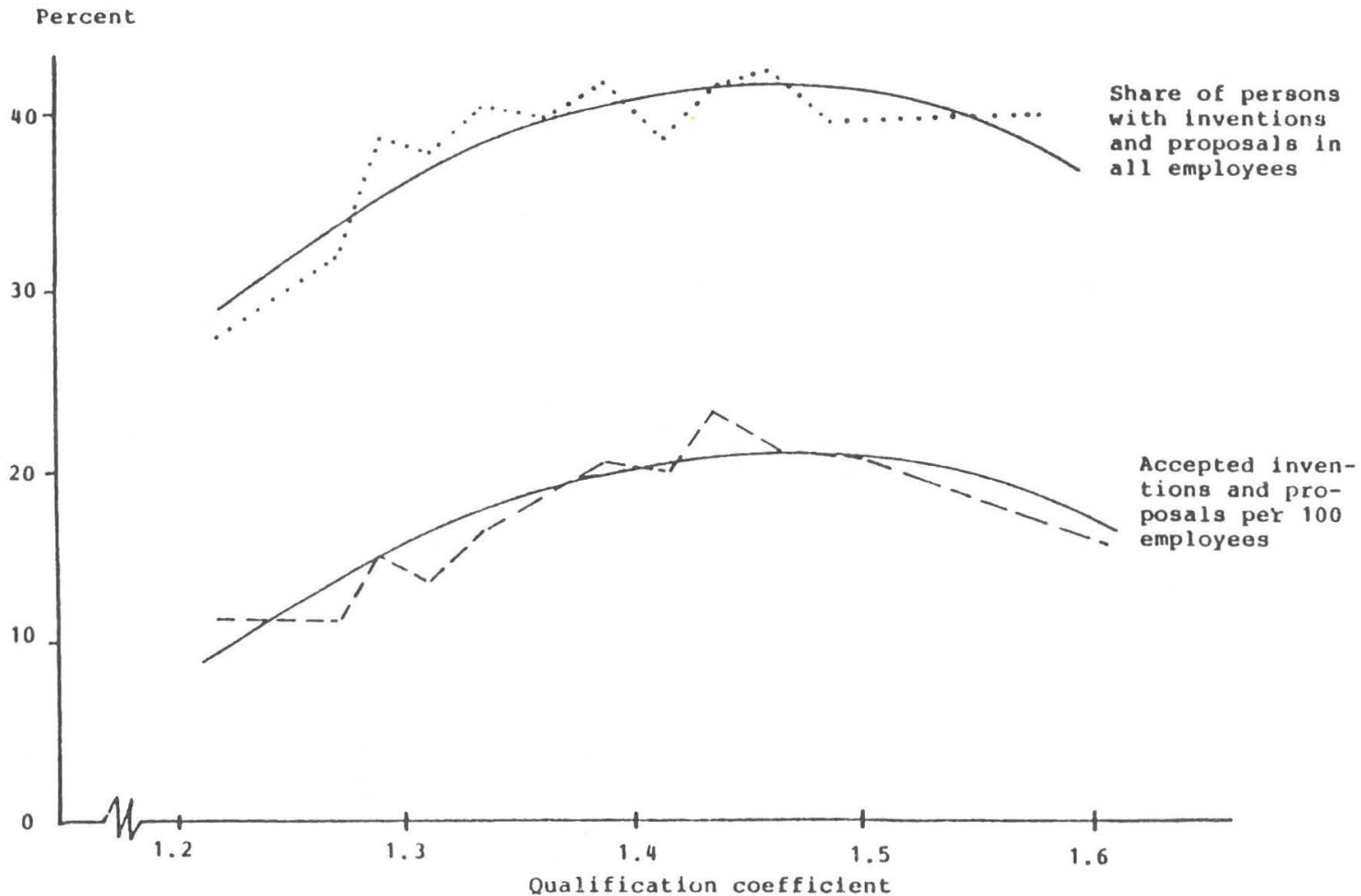

Fig. 6. Average qualifications coefficient: the use of adopted innovations per 100 employees and the share of innovations over all employees. [The qualifications coefficent is estimated by the reduction of highly skilled work over unskilled work. As weights for the different groups of qualified work, we used the reproduction costs of labor forces with different levels of qualification. For the methodology of estimating the qualification coefficient see Maier, Ludwig, and Wahse (1972).] 


\section{References}

1. Abernathy, W. J., The Productivity Dilemma. John Hopkins University Press, Baltimore, 1978

2. Bodde, D. L., Riding the Experience Curve, Technol. Rev. 539 (March-April 1976).

3. Häfele, W., Global Perspectives and Options for Long-Range Energy Strategies. Keynote address at the Conference on Energy Alternatives, East-West Center, Hawaii, January 9-12, 1979.

4. Haustein, H.-D., Complex Innovation in Lighting Industry (A Case Study on the Example of GDR Industry). WP-80-12. Laxenburg, Austria: International Institute for Applied Systems Analysis, 1980

5. Haustein, H.-D., and Maier, H., Basic, Improvement, and Pseudo-Innovations and Their Impact on Efficiency. WP-79-96. Laxenburg, Austria: International Institute for Applied Systems Analysis, 1979.

6. Haustein, H.-D., Maier, H., and Robinson, Jennifer, Appropriate Technology. WP-79-95. Laxenburg, Austria: International Institute for Applied Systems Analysis. Presented at IFAC Symposium for Selecting Appropriate Technologies Under Different Cultural, Technical, and Social Conditions, Bari, Italy, May 1979.

7. The Human Gap, The Learning Report to the Club of Rome, Pergamon Press, New York, 1979.

8. Kondratieff, N.D., Die langen Wellen der Konjunktur, in Archiv für Sozial-Wissenschaften und Sozialpolitik, Tüblingen, 56 Band, S. 573, 1926.

9. Maier, H., Some Conclusions for International Technology Assessment from the IIASA Energy Study, Invited paper for the XXIV International Meeting at the Institute of Management Science, Honolulu, Hawaii, June 1979.

10. Mensch, G., Das technologische Patt. Frankfurt am Main, 1975.

11. Norman, C., Massenproduktion oder Produktion durch die Massen, Europa Archiv 17, 539 (1978).

12. Utterback, J. M., The Dynamics of Product and Process Innovation in Industry. In Technological Innovation for a Dynamic Economy. Hill and Utterback, eds. Pergamon Press, New York, 1978.

Received 7 December 1979 
